\section{§16. Development of Highly Effective Cooling Technology for a Superconducting Magnet Using Cryogenic OHP}

Mito, T., Natsume, K., Yanagi, N., Tamura, H., Tamada, T., Shikimachi, K., Hirano, N., Nagaya, S. (Chubu Electric Power Co., Inc.)

It is actually difficult for a high-Tc superconducting (HTS) magnet to take out the heat generated in the winding, because the thermal diffusivities of each component materials of the magnet such as copper, aluminum alloy, epoxy resin, GFRP, etc., decrease with an increase of the operating temperature. Therefore, a local hot spot can be easily generated in the magnet, and there are possibilities of degradation of superconducting properties and/or mechanical damage by thermal stresses. A highly effective cooling technique for a superconducting magnet is proposed by incorporating the cryogenic oscillating heat pipes (OHP) as cooling panels in the coil windings as shown in Fig. 1. The OHP utilizes the pressure change in volume expansion and contraction during phase changes to excite the oscillation motion of liquid plugs and vapor bubbles between evaporator and condenser. The OHP is a high performance two-phase heat transfer device, which can transport several orders of magnitude larger heat loads than heat conduction of solids.

The cryogenic OHP using $\mathrm{H}_{2}, \mathrm{Ne}$, and $\mathrm{N}_{2}$ as working fluids have been developed and tested at the operating temperature ranges of $17-25 \mathrm{~K}\left(\mathrm{H}_{2}\right), 26-32 \mathrm{~K}$ $(\mathrm{Ne})$, and $67-80 \mathrm{~K}\left(\mathrm{~N}_{2}\right)$. The OHP consists of the stainless steel pipe of $1.59 \mathrm{~mm}(1 / 16$ inch) in outer diameter and $0.78 \mathrm{~mm}$ in inner diameter was turned 10 times by U-shape bend at both ends with its straight sections of $160 \mathrm{~mm}$ in length as shown in Fig. 2. Two $\mathrm{Cu}$ blocks of $8 \mathrm{~mm}$ in thickness and $30 \mathrm{~mm}$ in length had grooves according to the pipe positions and were soldered with the heat pipes. The upper $\mathrm{Cu}$ block attached with the foil heater was the heating part of OHP (evaporator) and the lower $\mathrm{Cu}$ block connected to the GM cryocooler was the cooling part of OHP (condenser) as shown in Fig. 3.

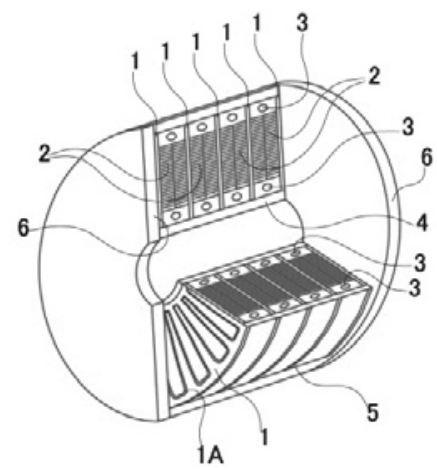

Fig. 1. Conceptual design configuration of an OHP imbedded HTS magnet, where 1: cooling panel, 1A: OHP, 2: coil windings, 3: cooling channels of refrigerant, 4 : inner bobbin, 5 : outer bobbin, 6 : end plates.
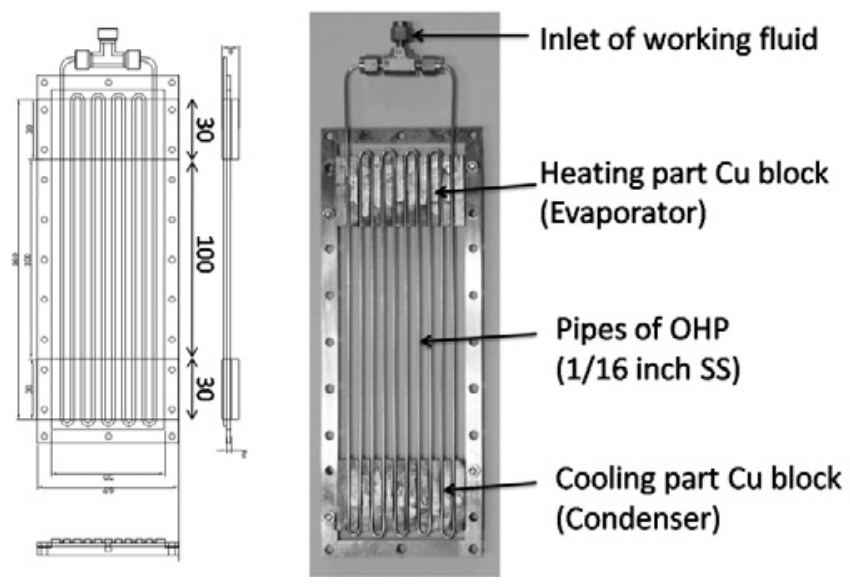

Fig. 2. OHP for cryogenic experiments.

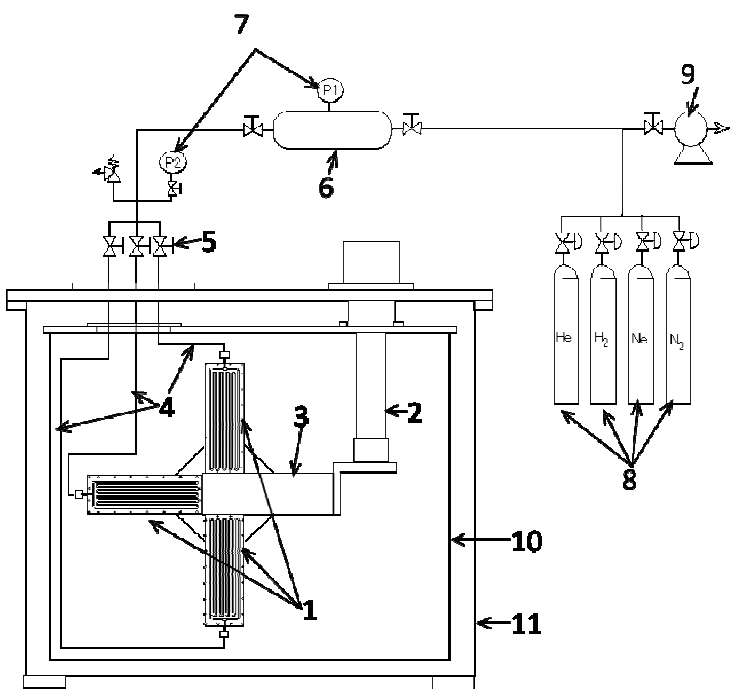

Fig. 3. Experimental set-up for cryogenic OHP, where 1: cryogenic OHP, 2: GM cryocooler, 3: Cu bus bar connecting OHP and GM cryocooler, 4: filling piping of working fluid, 5: isolation valves, 6: buffer tank, 7: pressure gauges, 8: gas cylinders of working fluids (He, $\mathrm{H}_{2}, \mathrm{Ne}, \mathrm{N}_{2}$ ), 9: vacuum pump, 10: radiation shield, 11: cryostat.

The measured effective thermal conductivities were reached to $500-3,000 \mathrm{~W} / \mathrm{m} \cdot \mathrm{K}\left(\mathrm{H}_{2}\right), 1,000-8,000$ $\mathrm{W} / \mathrm{m} \cdot \mathrm{K}(\mathrm{Ne})$ and $10,000-18,000 \mathrm{~W} / \mathrm{m} \bullet \mathrm{K}\left(\mathrm{N}_{2}\right)$. The high thermal transport properties of the cryogenic OHP have been demonstrated and its application as the highly effective cooling components of superconducting magnets can be performed.

1) T. Mito, K. Natsume, N. Yanagi, H. Tamura, T. Tamada, K. Shikimachi, N. Hirano, and S. Nagaya, "Development of Highly Effective Cooling Technology for a Superconducting Magnet Using Cryogenic OHP," IEEE Transactions on Applied Superconductivity, vol. 20, 2010, pp. 2023-2026.. 